\title{
FORMAÇÃO EM SERVIÇO DE PROFESSORES COMUNS E ESPECIALIZADOS E SUAS IMPLICAÇÕES NA PRÁTICA: UMA EXPERIÊNCIA DE CONSULTORIA COLABORATIVA
}

\author{
TRAINING SERVICE FOR COMMON AND SPECIALIZED TEACHERS \\ AND ITS IMPLICATIONS IN PRACTICE: A COLLABORATIVE CONSULTING \\ EXPERIENCE
}

\author{
Patricia Moralis CARAMORI ${ }^{\mathrm{i}}$
}

RESUMO: O trabalho traz parte dos resultados de uma pesquisa de abordagem qualitativa fundamentada na perspectiva participativa e interpretativa. Tem por objetivo oferecer formação continuada em serviço a professores regulares e de educação especial, sob o enfoque de consultoria colaborativa, tendo como base teórica os critérios de Experiência de Aprendizagem Mediada de Reuven Feuerstein. Por meio de filmagem, observação e reuniões reflexivas com participação de duas professoras do ensino comum e uma professora de educação especial, os resultados apontam para a importância do critério de mediação Significado. A prática da professora de $4^{\circ}$ ano mostra uma quebra no processo de transmissão do significado e, na reunião reflexiva, as estratégias discutidas, bem como a descrição de algumas práticas já empregadas pelas professoras, levam a um enriquecimento na formação e conhecimento sobre planejamento das atividades, pensando nos objetivos e sobre a importância do feedback tanto para o professor quanto para os alunos para que o significado se estabeleça.

PALAVRAS-CHAVE: Educação especial. Inclusão escolar. Experiência de aprendizagem mediada. Formação de professores. Consultoria colaborativa.

ABSTRACT: The work presents part of the results of a research with qualitative approach grounded on the participatory and interpretative perspective. Its aim is to offer regular and special education teachers in service continuing training on the collaborative consulting approach, having as theoretical basis the criteria of Reuven Feuerstein's Mediated Learning Experience. Through filming, observation and reflexive meetings with the participation of two teachers from regular education and one teacher from special education, results point to the importance of Meaning as a mediation criterion. The practice of the $4^{\text {th }}$ grade teacher shows a disruption in the process of meaning transmission. Besides, during the reflexive meeting, the strategies discussed, as well as the description of some practices already used by the teachers, bring to an enrichment in training and knowledge about planning activities with goals in mind and about the importance of feedback both to the teacher and to the students in order for meaning to establish itself.

KEYWORDS: Special education. School inclusion. Mediated learning experience. Teacher training. Collaborative Consulting. 


\section{Introdução}

Desde a década de 1990, com a assinatura de documentos internacionais, como a Declaração de Salamanca (UNESCO, 1994) e a partir da própria Lei de Diretrizes e Bases (LDB) (BRASIL, 1996), a adoção dos princípios da Inclusão Escolar vem exigindo mudanças nas posturas e atitudes dos professores de todo o país. O trabalho sob essa perspectiva, pautado nas políticas públicas, dá acesso à escola a um público diferenciado, com o qual o professor precisa aprender a trabalhar e, consequentemente, ensinar respeitando suas diferenças e limites.

A partir da Política Nacional de Educação Especial na Perspectiva da Educação Inclusiva (BRASIL, 2008), que vem nortear o Atendimento Educacional Especializado (AEE) nas escolas comuns, a legislação sobre a inclusão passa a se consolidar e, consequentemente, as ações dentro da escola são mais evidenciadas. A política traz informações como a quem é destinado o atendimento, como as escolas devem se organizar, entre outras coisas, ou seja, tem como objetivo o acesso, a participação e a aprendizagem dos alunos público-alvo da educação especial (PAEE) que hoje estão matriculados nas escolas comuns e frequentam as salas regulares. Seu sentido é de orientar o funcionamento das escolas para que estas ofereçam as melhores respostas a cada caso de necessidade desses alunos em suas realidades.

É inegável que o processo de inclusão escolar se encontra em curso, resultando em práticas que vem se consolidando, não só para os alunos incluídos, como também para os professores e para a comunidade escolar. Muitos são os vieses a partir dos quais a inclusão escolar é interpretada, como bem salienta Mazzota:

\footnotetext{
Atualmente, sob as mais variadas interpretações, a inclusão escolar tem mobilizado aqueles que a consideram uma ação impraticável e, também, os que a entendem como medida a ser imposta a todos em quaisquer circunstâncias individuais ou institucionais. Outros, como eu, a defendem como ação política e social implantada e desenvolvida com responsabilidade. (MAZZOTA, 2010, p. 81).
}

Em nível mundial, a inclusão é entendida como uma reforma educacional profunda e significativa, na qual não se pode tratar apenas de alterações no currículo ou facilitar o acesso de todos, indiscriminadamente. Trata-se de mudanças que exploram fatores mais arraigados, como valores e práticas de todo o sistema educativo 
(RODRIGUES; LIMA-RODRIGUEZ, 2011), assim como a própria concepção de escola.

No âmbito escolar este movimento incide na forma de se constituir o trabalho, pois passa a exigir análise e reflexão acerca de práticas de professores, gestores, coordenadores, orientadores ou qualquer outro profissional da educação. Para Rodrigues (2006), um programa de educação inclusiva está intimamente ligado às atitudes, à vontade, à ética, às iniciativas, aos valores e às práticas de quem trabalha diretamente com a diversidade dos alunos, além do compromisso de oferecer serviços de qualidade. Dessa forma, a identidade inclusiva vai se formando e, por meio da reflexão, a proposta é de que haja o desenvolvimento de meios para transpor as barreiras que se evidenciam no cotidiano e limitam a presença, a participação e a aprendizagem de todo e qualquer aluno do ensino regular. Deixa-se de lado o modelo clínico para adotar um modelo social que avalia a incapacidade do indivíduo como resultante da sua interação com o meio e considera o meio como a fonte geradora de obstáculos para o seu desenvolvimento, já que quase tudo ainda precisa de adaptação para receber os alunos com algum tipo de dificuldade na escola regular (NOGUEIRA; RODRIGUES, 2006).

Sua implantação e desenvolvimento na escola requerem um norte, como alguns princípios que Echeita e Ainscow (2011) descrevem para a melhor compreensão e consequente sucesso da inclusão. É preciso ter em mente que se trata de um processo, portanto não se consegue imprimir mudanças de um dia para o outro, além disso, é necessário saber o que buscar com a inclusão, ter clareza do que ela pode proporcionar e lutar para que isso aconteça, como a presença, a participação e sucesso do aluno, como estabelece a Política Nacional de Educação Especial na Perspectiva da Educação Inclusiva. A inclusão implica em identificar e eliminar as barreiras, pois na grande maioria das vezes são elas que impedem o acesso, a permanência e o progresso do aluno. Por último, é preciso ter clareza a quem se destinam as ações dispostas, pois aqueles que precisam desse tipo de atenção e intervenção costumam estar em uma zona de risco de exclusão do contexto escolar.

Os desafios da escola brasileira são identificados e não se limitam apenas a propiciar o acesso de todos, por meio da universalização de matrículas, mas estão ligados à garantia da máxima eliminação possível das barreiras relativas à aprendizagem e à participação efetiva de todos no processo educativo (MIRANDA, 2010). Vale lembrar que a educação inclusiva tem várias influências, sendo impulsionada pelas políticas sociais e educacionais, pela multiculturalidade, pela diversidade que está cada 
vez mais presente nas escolas e, principalmente, pela ruptura com os modelos tradicionais de ensino-aprendizagem, exigindo uma reinvenção ou reestruturação das práticas pedagógicas empregadas até então. Neste cenário, é preciso atender as dificuldades dos alunos em suas especificidades e resolver problemas referentes à diversidade inerente ao contexto escolar.

O processo de formação do professor, seja ela inicial ou continuada, está intrinsecamente ligado a essas rupturas e mudanças de postura e de prática que a inclusão exige, pois é um dos pilares do seu desenvolvimento profissional, refletindo diretamente no trabalho em sala de aula e nos resultados com os alunos. Sobre a formação continuada, de acordo com a LDB, fica a cargo dos sistemas de ensino o aperfeiçoamento profissional continuado dos professores, bem como a garantia de um período para estudos para o professor, incluído em sua carga horária de trabalho (BRASIL, 1996).

A Resolução CP/1 do Conselho Nacional de Educação que institui Diretrizes Curriculares em âmbito nacional para a formação de professores da educação básica atenta para a necessidade de formação continuada (BRASIL, 2002). Essa é uma característica importante da profissão docente, em vista da dinâmica do trabalho e dos agentes que influenciam diretamente a escola e sua população, fazendo da educação um exercício em constante mudança e aprimoramento. O texto da resolução aponta que a formação continuada deve ser vista como um retorno planejado e sistemático dos professores ao meio acadêmico, indicando essa busca constante de conhecimento, inerente à profissão.

É importante reconhecer as trocas entre professores também como um momento formativo, principalmente aquelas que acontecem nas situações de trabalho pedagógico coletivo. Faz-se importante também fazer com que o próprio professor identifique essa formação contando para seu desenvolvimento e aperfeiçoamento profissional.

Outra discussão importante acerca da formação e da prática docente é a da dicotomia entre teoria e prática que precisa ser superada. A relação entre a teoria, a prática e as experiências anteriores está diretamente ligada às aprendizagens significativas, que fazem parte tanto da formação do professor quanto da formação do aluno da educação básica. Se a busca pela transposição das teorias aprendidas nos bancos escolares para as práticas na vida cotidiana é um ponto importante para que as aprendizagens sejam efetivamente significativas para as crianças, essa também deve ser a lógica da formação de professores. 
Um ponto importante da formação continuada é que o conhecimento não venha apenas de fora para dentro da escola. Faz diferença na apreensão dos conhecimentos quando o professor tem a escola como lócus de formação, quando o saber docente é reconhecido e referenciado, considerando e valorizando a bagagem prática que o professor traz em sua formação e prática. Partindo desses pressupostos é possível construir as soluções com o que se tem disponível: profissionais bem orientados e capacitados e recursos possíveis.

Mesmo valorizando os conhecimentos dos professores, novas ideias e iniciativas podem ser inseridas nas práticas docentes buscando melhores caminhos para impulsionar o desenvolvimento e a aprendizagem dos alunos. Partindo do campo da Psicologia, Reuven Feuerstein desenvolveu a Teoria da Modificabilidade Cognitiva Estrutural (MCE) e, dentro dela, o conceito de Experiência de Aprendizagem Mediada (EAM), entre outras coisas.

Dentro dessa teoria, a mediação se define a partir do entendimento de outro conceito mais amplo, que abarca os de senso comum, mas é instituída com base em dois pressupostos: a) o organismo humano é um sistema aberto e de mudanças cognitivas controláveis; b) a modificabilidade cognitiva se explica pelos processos de experiência e intervenção cognitiva mediada (CASANOVAS, 2005).

A MCE trabalha com a capacidade dos seres humanos, sejam eles com deficiência ou não, de mudar, aprimorar e modificar sua estrutura de funcionamento cognitivo no sentido de acompanhar o ritmo de mudanças da vida. Os dois pressupostos que dão base à teoria de Feuerstein são intimamente relacionados, pois a palavra modificabilidade, que não existe no dicionário, é utilizada de forma intencional, sugerindo um avanço que vai além da mudança gerada pela maturação natural do indivíduo. O organismo humano é visto como capaz de obter mudanças cognitivas controláveis, porque a referida modificabilidade sugere uma intervenção no desenvolvimento do indivíduo, sendo definida como uma modificação estrutural no funcionamento cognitivo, que vai além do percurso natural esperado para cada idade. Trata-se da criação de novos mecanismos cognitivos que alteram a estrutura mental existente e que também se auto alteram. Somente é possível chegar a uma MCE a partir da EAM (CARAMORI, 2009).

A EAM trabalha com o conceito de mediação no qual estão inseridos dois elementos: o mediador e o mediado. A mediação é definida como um processo no qual um adulto mais experiente, ou o chamado mediador, se interpõe entre os estímulos e o 
organismo humano, modificando os estímulos para este indivíduo, o mediado. $\mathrm{Na}$ mediação, os estímulos são transformados pelo mediador, guiado por suas intenções, instituições, emoções e cultura, sendo selecionados os mais apropriados, filtrando-os, elaborando esquemas, ampliando alguns e ignorando outros (SANTOS; MARQUES, 2012). Controlando o mundo de estímulos para o mediado, o mediador pode usar estratégias diferentes, tais como: direcionar sua atenção, mudar a frequência do estímulo, sua ordem e intensidade, relacioná-lo a contextos próximos ao mediado, regular sua ordem e controlar sua frequência. (TZURIEL, 2008).

Com todos os benefícios que se estabelecem a partir da aplicação da mediação, é necessário deixar claro que este conceito, que perpassa diversas áreas, tem critérios préestabelecidos por Feuerstein para que seja reconhecido no contexto da EAM (GOMES, 2002). Estes critérios são, cada um deles, formas e estilos de interação, e cinco deles são essenciais para que a mediação ocorra, sendo eles: intencionalidade e reciprocidade; transcendência; significado; sentimento de competência e; regulação e controle do comportamento. Neste artigo será abordado apenas o critério significado, no qual o mediador, ao apresentar um estímulo ou um evento, enfatiza sua significação e valor expressando interesse e afeto, apontando a sua Importância e valor.

A consultoria colaborativa, que caracteriza a presente pesquisa, de acordo com Gomes e Lobato (2006), caracteriza-se por ser mais um modelo de suporte à educação inclusiva, no qual profissionais especializados, sejam professores de educação especial, psicopedagogos, fonoaudiólogos ou fisioterapeutas, estabelecem parcerias com os profissionais da escola em que há alunos com deficiências, altas habilidades/superdotação ou com transtorno global do desenvolvimento.

O objetivo parcial da pesquisa, que atende a esse artigo, é o de intervir no contexto escolar oferecendo formação continuada em serviço a professores regulares e de educação especial, sob o enfoque de consultoria colaborativa, tendo como base teórica os critérios de Experiência de Aprendizagem Mediada de Reuven Feuerstein. O propósito desta intervenção é o de identificar mudanças nas práticas dos professores participantes por meio da reflexão acerca dos problemas do cotidiano escolar enfrentados no trabalho voltado aos alunos público-alvo da educação especial. 


\section{Método}

Trata-se de uma pesquisa qualitativa de modo geral que tem como preocupação central da pesquisadora a vivência dos participantes, buscando uma descrição detalhada das situações, eventos, condutas ou pessoas envolvidas no processo investigativo. Além disso, fundamenta-se em uma perspectiva interpretativa calcada no entendimento do significado das ações de seus participantes diretos e indiretos (SAMPIERI; CALLADO; LUCIO, 2013).

Como conceito de estratégias pedagógicas, estabeleceu-se uma rede de significados a partir da definição da palavra estratégia, a qual foi buscada no dicionário:

3. P. ext. Arte de aplicar os meios disponíveis com vista à consecução de objetivos específicos.

4. P. ext. Arte de explorar condições favoráveis com o fim de alcançar objetivos específicos (HOUAISS; VILLAR, 2012).

Aproximando o termo à Educação, estratégias pedagógicas são definidas como ações executadas pelos professores, as quais funcionam como suporte, auxiliando a prática docente. Têm o papel de facilitar a aprendizagem do aluno, portanto, tornam-se imprescindíveis no desenvolvimento do trabalho docente (CARAMORI, 2009).

O estudo, em relação aos critérios de coleta de dados, caracteriza-se como participativo, já que propõe uma participação efetiva dos sujeitos envolvidos em um processo de geração e construção de conhecimento considerado procedimento de formação, tratando-se de formação continuada em serviço de professores (GONSALVES, 2003) com base nos preceitos da consultoria colaborativa. Também é de cunho exploratório, pois assim permite a familiarização com os sujeitos participantes e suas preocupações explicitados nas ações e opiniões dos professores durante um processo de formação continuada em serviço (POUPART et al., 2010), sob enfoque de uma consultoria colaborativa.

A pesquisa foi desenvolvida em uma escola localizada na área não urbana do município. Trata-se de uma escola de Ensino Fundamental, portanto atende cerca de 130 alunos do $1^{\circ}$ ao $9^{\circ}$ ano. Há uma sala de recursos multifuncional (SRM), lugar onde a professora de educação especial trabalha com os alunos, que está equipada com materiais específicos para atender alunos com deficiência intelectual, pois somente alunos com esta característica foram identificados para este atendimento. As participantes foram duas professoras do ensino regular, uma responsável pelo $1^{\circ}$ ano e 
outra pelo $4^{\circ}$ ano, mais a professora de Educação Especial responsável pela Sala de Recursos Multifuncional da escola.

$\mathrm{O}$ procedimento de coleta de dados se dá em três momentos diferentes. $\mathrm{O}$ primeiro deles são reuniões com as professoras nas quais são abordados os critérios de Mediação elaborados por Reuven Feuerstein na Teoria da Modificabilidade Cognitiva Estrutural e no princípio da Experiência de Aprendizagem Mediada, bem como discussões e reflexões sobre as práticas das professoras. As estratégias e ações que caracterizam cada um dos critérios de mediação utilizados para nortear os professores nesse primeiro momento são as estabelecidas por Mentis (1997). O segundo momento se estabelece em cinco sessões de filmagem das aulas de cada uma das professoras do ensino regular participantes. Nestas sessões também há registro no diário de campo pela pesquisadora atentando-se aos critérios de mediação a serem trabalhados em cada sessão. No terceiro momento volta-se às reuniões de discussão entre as professoras e a pesquisadora, tendo como base os trechos da filmagem das aulas selecionados pela pesquisadora, compondo a consultoria colaborativa.

As reuniões com discussões acerca da teoria e das atuações das professoras com base nas filmagens se dão com enfoque colaborativo baseado na vídeo-formação inserida no contexto da pesquisa, o que proporciona às professoras participantes analisar, de forma mais aprofundada, suas próprias práticas docentes. $\mathrm{O}$ enfrentamento de sua atuação de um ponto de vista externo à situação por meio da gravação permite ao professor refletir intrapsicologicamente, além de motivar a formação de uma consciência reflexiva favorecendo maior autonomia ao professor no decorrer de suas atuações. Este modelo de trabalho impulsiona o professor a ter mais profissionalismo e consolida a construção de uma identidade profissional do professor (IBIAPINA, 2008).

A análise dos dados ocorre também no sentido de extrair e evidenciar, qualitativamente, porém com foco nas ações das professoras participantes, as ações referentes ao conteúdo aprendido, discutido e refletido conjuntamente com a pesquisadora sobre a mediação. Essa análise tem o destaque de informações complementares registradas a partir da visão e da vivência da pesquisadora junto com as professoras, tanto dentro de sala de aula, no momento das filmagens, quanto nas reuniões de discussão e reflexão. 


\section{Resultados}

De acordo com os três momentos descritos no método, o primeiro contato da pesquisadora com as professoras foi o da reunião sobre a teoria, na qual a pesquisadora apresenta os critérios de mediação e as ações que caracterizam cada um deles. Sobre o critério Significado o quadro a seguir descreve essas ações.

Quadro 1: Estratégias que caracterizam o critério de mediação Significado

\begin{tabular}{|l|}
\hline \multicolumn{1}{|c|}{ Estratégias que caracterizam SIGNIFICADO } \\
\hline Organizar e estruturar as informações segundo o nível, interesse e necessidade dos alunos. \\
\hline Proporcionar o feedback necessário. \\
\hline Projetar situações para fomentar o ensino colaborativo. \\
\hline Explicitar a importância das tarefas. \\
\hline Ensinar os alunos a avaliar suas atividades com múltiplos critérios. \\
\hline Usar a exploração de alternativas para solucionar as tarefas. \\
\hline Ressaltar o valor das matérias para os alunos, para que servem. \\
\hline $\begin{array}{l}\text { Explicitar as estratégias e habilidades que devem ser utilizadas pelos alunos para solucionar a } \\
\text { tarefa. }\end{array}$ \\
\hline $\begin{array}{l}\text { Utilizar comportamentos não verbais para dar significado (posição, expressão facial, nível e } \\
\text { inflexão de voz). }\end{array}$ \\
\hline Reconhecer o significado das respostas dos alunos. \\
\hline
\end{tabular}

Fonte: Elaboração própria com base em Mentis (1997)

Sobre cada uma das estratégias, as professoras conversam com a pesquisadora indicando coisas que já fazem em sala de aula com seus alunos, discutindo possibilidades acerca do que pode ser feito para levar à prática do critério de mediação significado.

Nesse momento a pesquisadora reforça a ideia do uso do feedback tanto dos alunos quanto das professoras. Quando ele vem do aluno as professoras podem dar continuidade ao trabalho com mais clareza daquilo que foi aprendido. Mas quando o feedback vem do professor para o aluno este se baseia na resposta do aluno, ou seja, passa a ser um feedback do feedback. Nessa situação, o critério do significado pode ser favorecido e o aluno vê razão em seu aprendizado e seu progresso ou até mesmo encontra motivação para aprender quando vê sentido naquilo que está sendo ensinado.

Outro ponto que teve destaque na discussão foi o tema do trabalho colaborativo entre os alunos. A ideia é de que o professor não precisa ser o único foco e provedor de 
conhecimento em sala de aula, mas os alunos podem também aprender com seus pares, o que também facilita a aprendizagem. As professoras sinalizam seus receios em relação à indisciplina quando se fala em troca entre os pares, mas a pesquisadora fez indicações positivas acerca das possibilidades que as ajudas no mesmo nível, sem hierarquia, podem gerar na aprendizagem dos alunos.

Partindo das professoras participantes, a professora de $1^{\circ}$ ano destacou a importância que o significado tem na apreensão dos conteúdos por parte dos alunos. Foi utilizado o exemplo de um de seus alunos, que também é público-alvo da Educação Especial, o qual teve um desempenho significativo na leitura e na escrita depois que a professora começou a usar a cozinha experimental da escola com o emprego de receitas para que os alunos lessem, escrevessem e vivenciassem a experiência de fazer algum tipo de comida. A partir de uma aplicação da leitura e da escrita é que sua aprendizagem fez sentido para o aluno, que passou a aprender com mais facilidade e, assim, desencadeando o processo.

Em relação ao trecho da filmagem da aula das professoras, foi selecionada a situação em que a professora do $4^{\circ}$ ano explica a atividade a ser feita. Trata-se da identificação dos materiais dos quais são feitos determinados produtos da construção civil e da indústria automobilística. A professora dá todas as instruções acerca do que é para ser feito e oferece exemplos para que os alunos tenham compreensão plena da tarefa além de subsídios suficientes para a realização da mesma. Instantes antes de iniciarem a atividade, logo após as explicações, a professora pede que os alunos agrupem as carteiras para se sentarem em duplas, fazendo com que todos se dediquem a isso de forma intensa na discussão e escolha do parceiro, bem como na locomoção e deslocamento da carteira, fazendo com que a sala toda produza bastante ruído e se disperse em relação à atividade.

Depois do tempo necessário para que os alunos se acomodassem, todos retomaram a atividade. Porém, nesse momento, a professora passou a ser solicitada por quase todas as duplas sendo questionada sobre o que era para ser feito, pois os alunos não se lembravam mais do propósito da atividade. Isso também aconteceu com a dupla em que estava o aluno PAEE.

$\mathrm{Na}$ reunião de reflexão, todas as professoras participantes assistiram ao trecho descrito sobre a atuação da professora do $4^{\circ}$ ano. Diante da gravação ela admitiu que o sentido da atividade se perdeu diante da mudança de dinâmica para realização da mesma, ainda que o significado possa ter se estabelecido nas explicações e exemplos 
oferecidos antes dessa situação. O problema possui dois pilares: o primeiro é que a professora não se certificou que os alunos haviam realmente captado o significado da atividade, ou seja, não houve a validação do significado transmitido; o segundo é a interrupção do processo com a mudança de dinâmica, a qual deveria ter ocorrido antes das instruções e informações acerca da tarefa a ser realizada para que o significado fosse passado pela professora e apreendido pelos alunos.

As outras professoras participantes contribuíram dando exemplos de soluções utilizadas quando algo parecido acontece em suas práticas. Por exemplo, a professora de $1^{\circ}$ ano, quando percebe que é necessário retomar as mesmas explicações individualmente, costuma fazer com que os alunos parem a atividade e, então, oferece a explicação para todos novamente, assim evita ter que ir de carteira em carteira repetindo a mesma coisa várias vezes.

O exemplo da professora de $1^{\circ}$ ano é uma forma de recobrar o significado da atividade ou daquela aprendizagem fazendo com que os alunos mantenham o sentido daquilo que estão fazendo. Essa colaboração da professora de $1^{\circ}$ ano reforça os modelos de práticas que caracterizam as ações de mediação de significado para além das trazidas pela pesquisadora, advindas da literatura e que já fazem parte do cotidiano daquela escola.

\section{Conclusão}

Como conclusão é possível indicar a necessidade de se deixar claro para o aluno o significado daquilo que está sendo trabalhado, seja uma atividade ou um assunto novo a ser ensinado. Quando o professor consegue passar esse sentido para os alunos todas as tarefas são realizadas com mais fluidez. No caso, a interrupção da dinâmica na realização desfavoreceu o processo de compreensão dos alunos. O planejamento da professora deveria ter previsto este tipo de interferência, caso contrário, a atividade teria seus contratempos, tal como ocorreu.

Essa interrupção fez com que o feedback se descontinuasse e até mesmo a utilização do trabalho colaborativo entre os alunos não favoreceu a manutenção do significado. Se a intenção da dinâmica de trabalho em dupla era a de favorecer a aprendizagem do aluno PAEE e, consequentemente, a do restante dos alunos, nota-se que essa estratégia também não foi bem-sucedida. 
Quando se tem em mente a transmissão do significado daquilo que se ensina algumas estratégias devem ser consideradas, como: "organizar e estruturar as informações segundo o nível, interesse e necessidade dos alunos"; "explicitar a importância das tarefas"; "ressaltar o valor das matérias para os alunos, para que servem"; "utilizar comportamentos não verbais para dar significado (posição, expressão facial, nível e inflexão de voz) ". A combinação dessas estratégias leva a uma preocupação com a ordem das instruções, mas a maior preocupação da professora de $4^{\circ}$ era o controle da turma e sua atenção, concorrendo com as formas de passar o significado.

Para além dos conteúdos da teoria de mediação e sobre o critério significado, bem como das discussões acerca da prática desses conhecimentos, as trocas de experiência entre as professoras também caracterizam um momento de formação dessas profissionais. Nesse caso, o aprendizado não vem somente de assuntos novos, mas das práticas utilizadas por colegas de trabalho que atuam próximos, porém não necessariamente são conhecidos pelos colegas.

\section{Referências}

BRASIL, Ministério da Educação. Lei 9.394/96. Lei de Diretrizes e Bases da Educação Nacional. Brasília: MEC, 1996

Resolução CNE/CP 1, de 18 fev. 2002. Institui as Diretrizes Curriculares Nacionais para a Formação de Professores para Educação Básica, em nível superior, curso de licenciatura, de graduação plena. 2002. Disponível em: <http://portal.mec.gov.br/cne/arquivos/pdf/rcp01_02.pdf >. Acesso em: 09 out. 2013.

. Política Nacional de Educação Especial na Perspectiva da Educação Inclusiva. Inclusão: Revista da Educação Especial, Brasília: CIBEC/MEC, v.4, n. 1, 2008a.

CARAMORI, P. M.; Estratégias pedagógicas para alunos com deficiência mental severa: um estudo sobre a atuação de professores de educação especial. 196f. Dissertação (Mestrado em Educação Escolar) - Universidade Estadual Paulista, Faculdade de Ciências e Letras, Araraquara, 2009.

CASANOVAS, M. A. M. Desarrollo de capacidades en alumnos gitanos en educación primária. 564f. Tese (Doutorado em Educación) - Universidad Complutense de Madrid, Madrid, 2005.

ECHEITA, G.; AINSCOW, M. La educación inclusiva como derecho. Marco de referencia y pautas de acción para el desarrollo de una revolución pendiente. Tejuelo, $\mathrm{n}$. 12, p. 26-46, 2011. 
GOMES, C. M. de A., Feuerstein e a construção mediada do conhecimento. Porto Alegre: Artmed, 2002.

GOMES, C. G. S., LOBATO, R. D. C. A inclusão escolar de crianças com autismo: o papel da consultoria colaborativa. In: Seminário Internacional Sociedade Inclusiva, n. 4, 2006, Belo Horizonte. Anais do IV Seminário Internacional Sociedade Inclusiva. Propostas e ações inclusivas: impasses e avanços. Belo Horizonte, 2006.

GONSALVES, E. P. Iniciação à pesquisa científica, Campinas: Editora Alinea, $3^{\text {a }}$ ed., 2003.

HOUAISS, A.; VILLAR, M. de S.; Dicionário Houaiss da Língua Portuguesa, 2012. Disponível em: <http://houaiss.uol.com.br> Acesso em: 04 jun. 2016.

IBIAPINA, I. M. L. de M. Pesquisa colaborativa: investigação, formação e produção de conhecimentos. Brasília: Liber livros Editora, 2008.

MAZZOTA, M. J. da S.; Inclusão escolar e educação especial: das diretrizes à realidade das escolas. In: MENDES, E. G., ALMEIDA, M. A. (ORG.). Das margens ao centro: perspectivas para as políticas e práticas educacionais no contexto da educação inclusiva. Araraquara: Junqueira e Marin, 2010, p. 79-88.

MENTIS, M. Aprendizagem mediada dentro e fora de sala de aula . São Paulo: Instituto Pieron de Psicologia Aplicada, 1997.

MIRANDA, M. de J. C. Educação Infantil: percepção de profissionais e familiares sobre inclusão, aprendizagem e desenvolvimento de crianças com deficiência, em Maringá/Br e em Guadalajara/ES. 495f. Tese (Doutorado em Educação Escolar) Universidade Estadual Paulista, Faculdade de Ciências e Letras, Araraquara, 2010.

NOGUEIRA, J. H. B.; RODRIGUES, D. A educação da criança com deficiência mental profunda na escola regular e na escola especial: avaliação de dois modelos. In:

POUPART, $\mathrm{J}$ et al A pesquisa qualitativa: Enfoques epistemológicos e metodológicos. 2.ed. Tradução de Ana Cristina Arantes Nasser. Petrópolis: Vozes, 2010.

RODRIGUES, D. Investigação em educação inclusiva. V. 1, Cruz Quebrada Portugal: Faculdade de Motricidade Humana Serviços de Edições, p. 137-158, 2006.

RODRIGUES, D. Dez ideias (mal) feitas sobre a educação inclusiva. In: RODRIGUES, D. Educação Inclusiva: estamos a fazer progresso? Cruz Quebrada - Portugal: Faculdade de Motricidade Humana Serviços de Edições, p. 299-318, 2006.

RODRIGUES, D. LIMA-RODRIGUEZ, L. Formação de professores e inclusão: como se reformam os reformadores? In: RODRIGUES, D. (ORG) Educação Inclusiva: dos conceitos às práticas de formação. Lisboa: Instituto Piaget, p. 89-108, 2011.

SAMPIERI, R. H., CALLADO, C. F., LUCIO, M. del P.B., Metodologia de pesquisa. 5 ed., Tradução de Daisy Vaz de Moraes, Porto Alegre: Penso, 2013. 
SANTOS, S. B. dos; MARQUES,M. do P. S. D.; Contribuições de Reuven Feuerstein para a Educação Especial na perspectiva da Educação Inclusiva. In: Congresso Brasileiro de Educação Especial, n 5. 2012, São Carlos. Anais do V Congresso Brasileiro de Educação Especial; VII Encontro da Associação Brasileira de Pesquisadores em Educação Especial. São Carlos, 2012.

TZURIEL, D. Developmental Perspectives of Mediated Learning Experience Theory. In: KOZULIN, A. RAND. Y. (ed.), The Experience of Mediated Learning: an Impact of Feuerstein's Theory in Education and Psychology. Bingley: Emerald, p. 385-435, 2008.

UNESCO, Declaração de Salamanca e linha de ação sobre necessidades educativas especiais. Resultado da conferência mundial sobre necessidades educativas especiais: acesso e qualidade. Salamanca, Espanha, 1994. Disponível em: <http://portal.mec.gov.br/seesp/arquivos/pdf/salamanca.pdf> Acesso em: 04 jun. 2016.

Agradecimentos - à Coordenação de Aperfeiçoamento de Pessoal de Nível Superior (CAPES) pelo financiamento da pesquisa

\section{Como referenciar este artigo}

CARAMORI, Patrícia Moralis. Formação em serviço de professores comuns e especializados e suas implicações na prática: uma experiência de consultoria colaborativa. Revista Ibero-Americana de Estudos em Educação, v. 11, n. esp. 2, p.1034-1047, 2016. Disponível em: <https://dx.doi.org/10.21723/riaee.v11.esp2.p10341047>. E-ISSN: 1982-5587.

\section{Sobre os autores}

${ }^{i}$ Pós-doutoranda em Educação Especial. UFSCAR - Universidade Federal de São Carlos. Programa de Pós-Graduação em Educação Especial. São Carlos - SP - Brasil. 13560-001 - p.caramori@ gmail. com 